\title{
An Evaluation of Common Method Variance-Bias in Psychology
}

\author{
Leila Karimi ${ }^{1} \&$ Denny Meyer ${ }^{2} \mathrm{PhD}$ \\ ${ }^{1}$ Associate Professor, School of Psychology and Public Health, La Trobe University, Australia; Faculty of Social \\ and Political Sciences, Ivane Javakhishvili Tbilisi State University, Georgia \\ ${ }^{2}$ The Brain and Psych Sciences Centre, Swinburne University of Technology, Hawthorn, Australia \\ Correspondence: Leila Karimi, Associate Professor, School of Psychology and Public Health, La Trobe \\ University, Australia; Faculty of Social and Political Sciences, Ivane Javakhishvili Tbilisi State University, \\ Georgia. E-mail: 1.karimi@latrobe.edu.au
}

Received: June 14, 2019

Accepted: August 19, 2019

Online Published: August 30, 2019

doi:10.5539/ijps.v11n3p83

URL: https://doi.org/10.5539/ijps.v11n3p83

\begin{abstract}
This study demonstrated a novel procedure for assessing the significance of common method bias (CMB) using Structural Equation Modelin (SEM). It appears that CMB has a marked effect on the reliability of the measurement models. A new procedure using covariate-based reliability was proposed for assessing the effects of CMB on the reliability of a model. Further SEM analysis using marker variable procedure supports the presence of CMB in this study. This seems to be an interesting area to be explored in further research.
\end{abstract}

Keywords: wellbeing, covariate-based reliability, common method bias, Structural Equation Modeling, health sciences

\section{Introduction}

The widespread use of single-source data collection tools is a potential concern in relation to common method bias (CMB) which has been of interest in psychology since the 1950s. There is a widespread belief among scholars that measurement error is a problem source (Podsakoff, MacKenzie, Lee, \& Podsakoff, 2003). Measurement error has the ability to misrepresent and confound the empirical findings of research, causing erroneous conclusions to be drawn (Bagozzi \& Yi, 1991). This issue becomes more salient when researchers rely on a single source of data collection and self-report measures (Glick, Jenkins, \& Gupta, 1986; Meade, Watson, \& Kroustalis, 2007).

One of the more popular and most convenient procedures in psychology for collecting data is self-rated questionnaires (Malhotra, Kim, \& Patil, 2006). It is also a common practice in psychology that data is gathered from a single self-rated questionnaire (Avolio, Yammarino, \& Bass, 1991). As a result, CMB appears to be a common problem in psychological studies (Malhotra, et al., 2006). Yet, despite its long history in the psychology field, there seems to be a gap in the literature on CMB. To date, the literature has paid more attention to post-hoc statistical remedies, while the causes of the bias have been neglected. Also, no major study has been identified to determine the effects of CMB on reliability. The aim of this study is to address the current gap in literature on CMB using a newly developed procedure 'covariate-based and covariate-free reliability' (Bentler, 2014).

Acquiescence is a potential source of bias that results from self-report (Spector, 2006). According to Winkler, Kanouse and Ware (1982), acquiescence response refer to the propensity of the respondent to indicate agreement with items on the questionnaire independent of content.

Results from self-report measures are susceptible to social desirability. Social desirability describes the inclination of the respondent to complete the questionnaire in a way which enables them to be presented in a positive light and to be in line with the norms and standards defined by their culture (Donaldson \& Grant-Vallone, 2002; Ganster, Hennessey, \& Luthans, 1983; Podsakoff \& Organ, 1986). Their responses to questions are usually determined by the social desirability (Schriesheim, Kinicki, \& Schriesheim, 1979) of the items. This form of bias usually serves to hide the true bivariate relationships between variables (Ganster, et al., 1983; Podsakoff, et al., 2003).

One of the preventive techniques for detecting and controlling CMB is used when the assumed cause of the method bias is known to the researcher and it can be identified and measured (e.g. social desirability). In this 
way, the effects of the surrogate measure for CMB (e.g. social desirability) will be assessed by its effects on reliability of the study measures.

\subsection{The Effects of CMB on Reliability of Measures}

Based on the literature, CMB might affect the validity of a study (Doty \& Glick, 1998). It has the ability to confound the true relationship between variables, resulting in a bias between the observed and the true relationships by either inflating or deflating the estimates (Doty \& Glick, 1998). Although assessing the presence and quality of $\mathrm{CMB}$ provides important information on the effects of $\mathrm{CMB}$ on the parameter estimates, it does not demonstrate the effects of CMB on scale reliability. As suggested by Williams et al. (2010), it is probable that the reliability of a scale may also be affected by CMB. They proposed that the evaluation of the reliability should be achieved by evaluating the decomposition of the overall reliability, including and excluding the "marker variable" used to reflect CMB. The reliability decomposition formula was originally proposed by Williams and Paglis in 1997 and Cavazotte and Williams in 2002 (cited at Williams et al., 2010) as an extension of the formula provided by Werts, Linn, and Joreskog (1974).

Overall reliability $=$

$$
\frac{F}{F+E}
$$

When

$$
\begin{gathered}
F=\text { Sum Squared Factor Loadings for the scale items } \\
E=\text { Sum Error Variance for the scale items }
\end{gathered}
$$

There are two main limitations with the reliability decomposition formula. First, in practice there is no software to calculate this type of reliability and it needs to be done manually. This not only makes it hard to use the procedure more frequently but also involves some degree of errors. Second, although the reliability decomposition formula seems to be a correct procedure, it needs to be treated with caution first when substantive factors are uncorrelated with each other, and second when substantive and method factors are mutually uncorrelated.

In the present study, a newly developed approach by Bentler (2014) was used to compare the reliability of the measurement models in the presence of CMB. The procedure is simple and easy to calculate using EQS. What comes next is a brief introduction to this procedure.

\subsection{Bentler's Approach to Covariate-Based and Covariate-Free Reliability Coefficient rho.}

Recently, Bentler (2014) introduced the concept of covariate-dependent and covariate-free reliability. Bentler (2014; personal communications, 2012, 2013) defines the covariate-dependent reliability as " $\ldots$ a measure of the group differences on the trait being measured relative to total variation, while the covariate-free reliability is a measure of the reliable individual difference variance freed from any mean differences due to the groups, when the covariate is defined as a group variable."

Suppose a model contains one or more $\mathrm{Z} \rightarrow \mathrm{F}$ paths, the covariate-free rho is:

$$
\rho_{X X}^{\perp Z}=\frac{\Delta \cdot\left(1^{\prime} \Lambda\right)^{2}}{1^{\prime} \Sigma 1}
$$

The covariate-dependent or covariate-based rho can be be calculated as:

$$
\rho_{X X}^{(Z)}=\frac{\left(\gamma^{\prime} \phi \gamma\right)\left(1^{\prime} \Lambda\right)^{2}}{1^{\prime} \Sigma 1}
$$

$l^{\prime} \Sigma 1$

is the sum of all the elements in the model-reproduced covariance matrix of the X-variables. $\rho_{X X}$ represents the proportion of construct-based variance to the total variance of the sum score.

\subsection{Interpretation of Covariate-Dependent Reliability.}

The traditional view of reliability is defined as a measure of stable individual difference variation (if the data comes from individuals) relative to total variation. But in Bentler's view (2016), “... any individual score might be influenced by other sources, including group and other individual differences". 
This new method will be used to assess the influence of social desirability (method bias factor) on the reliability of constructs used in this study. Therefore it is hypothesised that:

Hypothesis: A covariate-based reliability assessment using social desirability, as a potential source of bias, demonstrates the effects of $\mathrm{CMB}$ on the reliability of the constructs in the study (Figure 1).

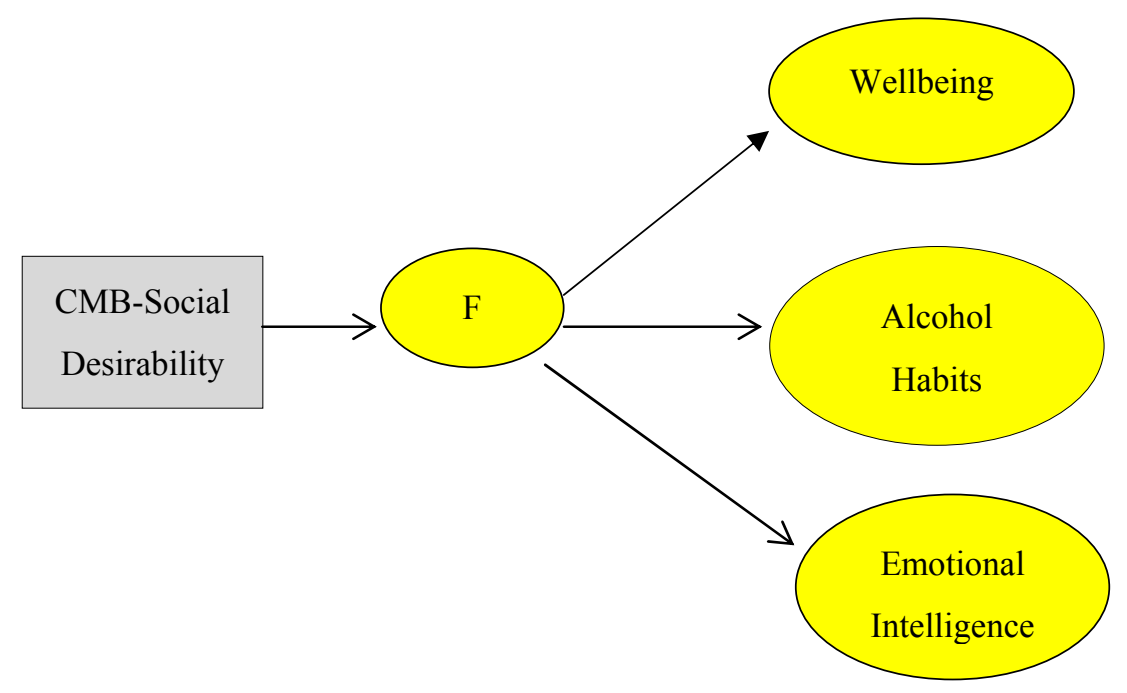

Figure 1. The proposed covariate-based reliability of the measures controlling for CMB (social desirability).

Further analysis will be supplemented to provide more support for the reported results.

An integrated preventive and post-hoc model will be adapted to control for CMV and CMB using SEM procedures. By integrating both unmeasured latent and directly measured latent method factors, CMV and CMB will be further evaluated (Figure 2). The method biases include rater's bias, and a single source self-reporting survey. Social desirability is a potential source of rater bias in the responses. The main constructs of the study contained sensitive questions (emotional intelligence, wellbeing and alcohol drinking habits), prompting participants to demonstrate socially acceptable responses rather than presenting their true opinions. Socially desirable responses could therefore be a type of bias for the relationships between the constructs of the study (Ganster, Hennessey \&Luthans, 1983). Based on the literature, if factor or item responses are highly correlated with social desirability, then social desirability could be a potential source of bias in the study that needs to be controlled (Podsakoff et al., 2003; Thomas \& Kilmann, 1975).

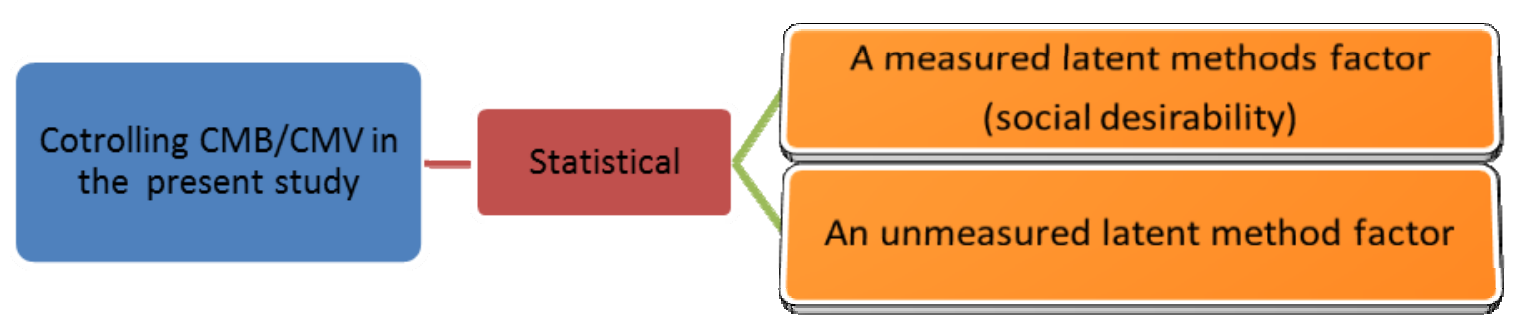

Figure 2. Integrating two statistical procedures for controlling $\mathrm{CMB} / \mathrm{CMV}$ in the present study. 
Figure 4a shows how this approach can be used in the context of a study involving wellbeing, drinking behaviour and emotional intelligence. This structural model suggests that CMV is caused by a social desirability bias (a CMB). This social desirability bias is measured using 16 items, parcelled into three scales, consisting of two to four items each, for model identification purposes.

It is hypothesised that:

Hypothesis 2: A SEM integrated approach including an unmeasured latent common method factor and a directly measured latent method factor (social desirability) can be used to evaluate the presence of CMV in the above context.

To evaluate this hypothesis both constrained (equal-method factor loadings) and unconstrained (free-method factor loadings) models will be assessed to find out if CMV exists and whether it has equal effects on the constructs of the study.

A partial correlation procedure can be used to test for CMV. More recently, a partial correlation technique is provided by Lindell and Whitney (2001). Using this procedure, a marker variable representing CMV is included in the analysis. Using a partial correlation procedure, the correlation between the marker variable and any construct in the model is used as an estimate of CMV. This allows all correlations among the constructs of the study to be corrected for CMV using a partial correlation adjustment (Williams, Hartman, \& Cavazotte, 2010). This method is called the correlational marker technique by Richardson et al., (2009). Building on the partial correlation procedure of Lindell and Whitney (2001), further development has been carried out by Richardson et al., (2009) and Williams, Hartman, \& Cavazotte (2010) by using a structural equation modelling procedure for capturing and adjusting for CMV. This marker variable procedure using CFA will be used to evaluate hypothesis 2 .

\section{Method}

\subsection{Sample}

The data for this study was collected from a group of undergraduate students studying in the same faculty of the participating university. Participants were randomly selected using a list of all the active subjects in the faculty for Semester Two, 2011. Upon receiving the lecturer's consent, a questionnaire package that included a cover letter, information sheet, consent form, and questionnaire were provided to each student during their lecture break. The information sheet provided assurances that all participant information would remain confidential. Upon completion of the survey students were asked to place their questionnaires in the locked box provided in the classroom. After discarding the incomplete surveys, the final number of surveys included in the analysis was 341 .

\subsection{Data Collection Procedure and Measures}

The questionnaire contained questions relating to wellbeing, drinking behaviour, emotional intelligence, social desirability and demographics.

Emotional Intelligence. Emotional intelligence was measured using the 33-item Self-Report Emotional Intelligence Test (SREIT) (Schutte, Malouff, Hall, Haggerty, Cooper, Golden, \& Dornheim, 1998). On a five-point Likert scale, respondents were asked to self-report their preferences on a scale from 1 (strongly agree) to 5 (strongly disagree). The reliability and validity evidence for this scale is positively assessed in previous studies (e.g. Schutte \& Malouff, 1999; Abraham, 1999; Ciarrochi, Chan, \& Caputi, 2000; Petrides \& Furnham, 2000).

General Wellbeing. General wellbeing was tested using the General Wellbeing Questionnaire (GWBQ) (Cox, Thirlaway, Gotts, \& Cox, 1983). The GWBQ is a 24-item instrument used to measure sub-optimal health, using self-reported symptoms of general malaise. It includes a set of general, non-specific symptoms of ill-health including reportable aspects of cognitive, emotional, behavioural and physiological function, none of which are clinically significant in themselves. The GWBQ consists of two 12-item subscales of sub-optimum health: (a) wornout/exhausted and, (b) tense/nervous. Respondents were asked to indicate how often they had experienced the following 24 symptoms within the previous six months on a scale from 0 (never) to 4 (all the time).

Social Desirability. The 16-item Social Desirability Scale (SDS-16) (Stöber, 2001) was used to measure the social desirability of the respondents. The scale is presented with six reverse-keyed items. The original scale has 17 items, but one item "I have tried illegal drugs" (e.g marijuana, cocaine, etc.) was excluded because it is not suitable for the measurement of social desirability. (Stöber, 2001). Items were parcelled into three scales in order to achieve SEM model identification. 
Alcohol Drinking Behaviour Screening. The World Health Organisation's Alcohol Use Disorders Identification Test (AUDIT) is a screening tool used for alcohol drinking behaviour screening. AUDIT was originally developed by Saunders, Aasland, Babor, de la Fuente, and Grant in 1993 and was validated extensively across different populations. It consists of three items on alcohol consumption, three on drinking behaviour and dependency, and four on the consequences or problems related to drinking. The items were parcelled into three items to achieve model identification.

\subsection{Overview of Data Analysis}

Confirmatory factor analysis (CFA) was conducted to evaluate the proposed model. Data were analysed using a software called EQS version 6.2 (built 100) and standard-fit indices (CMIN/DF, CFI, RMSEA) were used to evaluate the model fit. For reliability assessment and comparison, coefficient rho, and covariate-based and covariate-free reliability coefficients were used.

In SEM, by default, ML is used for parameter estimation. When the sample size is large and data are normally distributed, ML provides the most accurate estimation with the smallest standard errors (Bentler, 2006). However ML is sensitive to departures from normality. Therefore, assessment of normality is an essential requirement when using this procedure. Although the preliminary assessment of the data showed a relatively normal distribution for the data, Mardia's normalised coefficient was too high (Mardia's coefficient $(\mathrm{G} 2, \mathrm{P})=$ 216.79), indicating a violation of the normality assumptions. Outliers were detected in further analysis but their deletion did not result in significant improvement in the fit indices.

As a result, all the cases were kept and a suitable, non-parametric test was used to evaluate the model. The Satorra-Bentler $(1988,1994)$ chi-square test delivers a more accurate assessment of model fit when the data does not have a normal distribution.

\section{Results}

The demographic characteristics of the participants at both time points are presented in table 1 .

Table 1. Summary of the demographic characteristics of the participants

\begin{tabular}{ccc}
\hline & & Time $1(n=341)$ \\
& & 18.18 \\
\hline Gender & Male & 81.82 \\
& Female & 2.64 \\
Study status: Part-time & 97.36 \\
Full-time & $20.85(3.98)$ \\
\hline
\end{tabular}

Using covariate-based and covariate-free reliability analysis (Bentler, 2014), the overall reliability of the model, with or without CMB (social desirability) (Figure 3), was initially evaluated. 


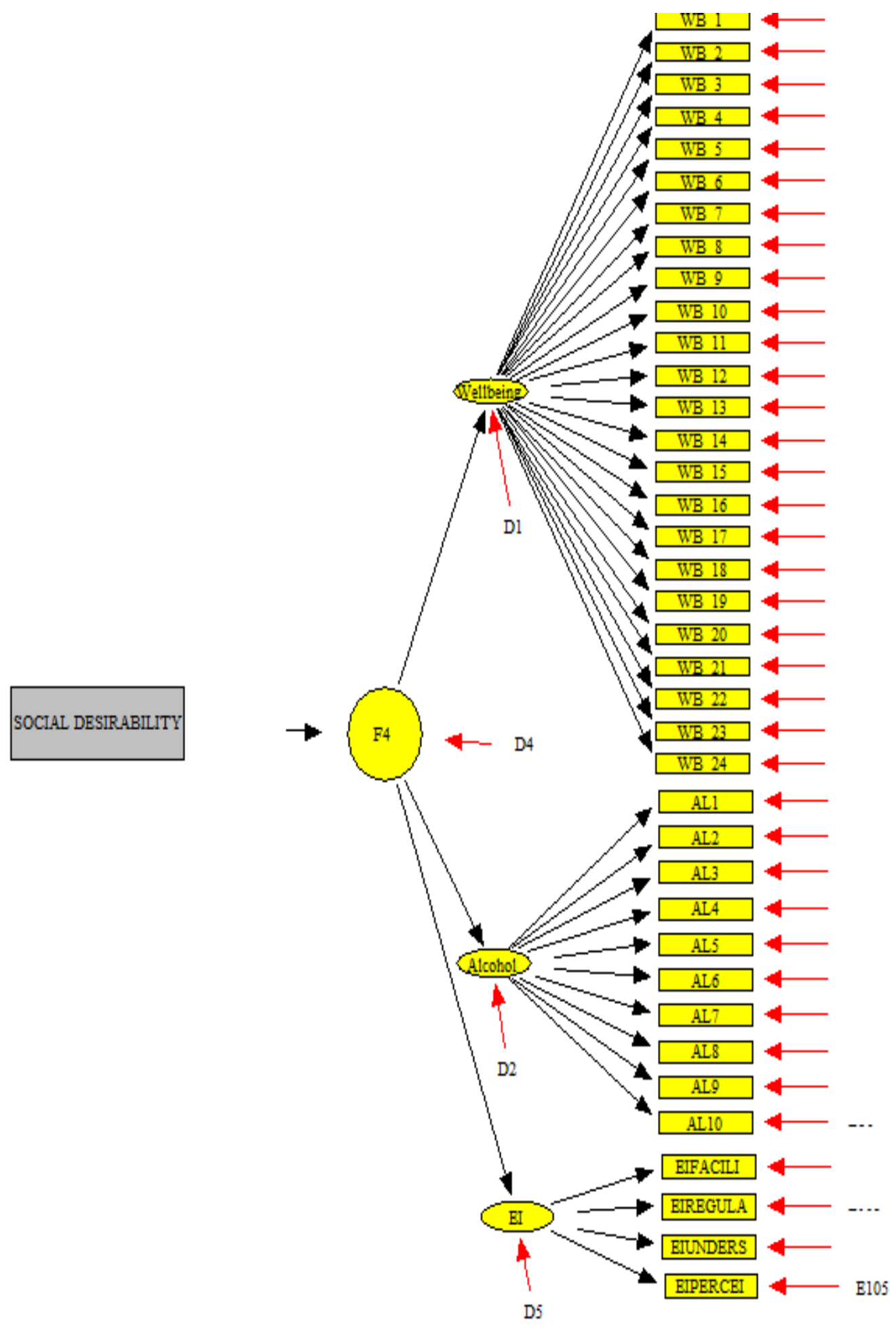

Figure 3. The effects of latent factor bias (social desirability) on the reliability of the constructs.

Notes: Due to the identification issue, item parcelling was used for the emotional intelligence (EI) construct allowing four EI subfactors to load as observed variables for this construct.

The effect of social desirability is assessed by performing the above reliability calculation, with and without social desirability. 
If there is a difference in the reliability coefficients of the constructs, with or without accounting for CMB, then we could conclude that the social desirability (CMB) has biased the reliability of the constructs.

Table 2. Comparison of the covariate-based and covariate-free reliability coefficients of the constructs

\begin{tabular}{cccc}
\hline Reliability Coefficients & $\begin{array}{c}\text { Overall } \\
\text { reliability }\end{array}$ & $\begin{array}{c}\text { Covariate-based } \\
\text { reliability }\end{array}$ & $\begin{array}{c}\text { Covariate-free } \\
\text { reliability }\end{array}$ \\
\hline All constructs in the model & .84 & .18 & .66
\end{tabular}

As presented in Table 2, the CMB variable (social desirability) inflated the reliability of the model by around 18 per cent. Removing the effect of CMB reduces the reliability of the model to only 0.66 . This result suggests that CMB has a remarkable effect on reliability, providing support for the study hypothesis.

Further analysis was supplemented to provide more support for the above reported results.

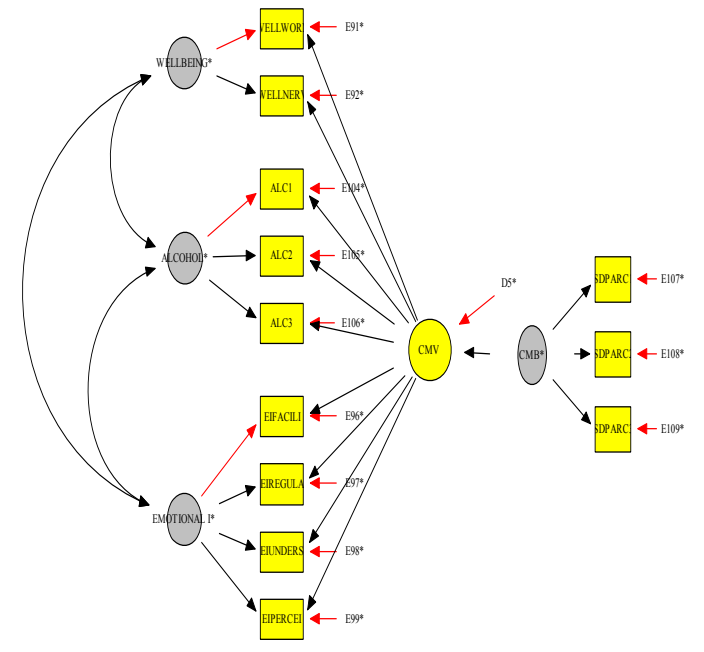

a. Proposed model for assessing CMV/CMB

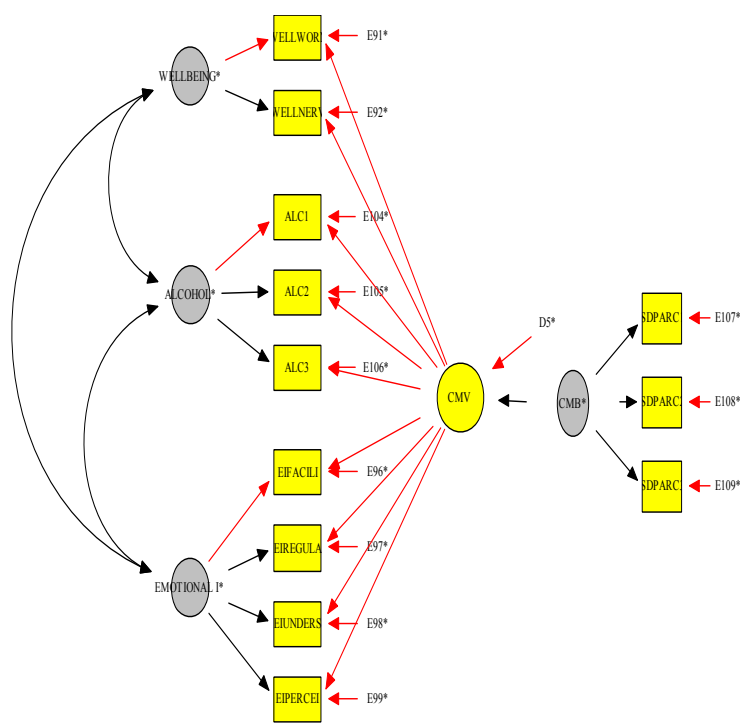

c. Model 2. An integrated model of CMV and CMB with constrained equal loadings from $\mathrm{CMV}$ to the study indicators.

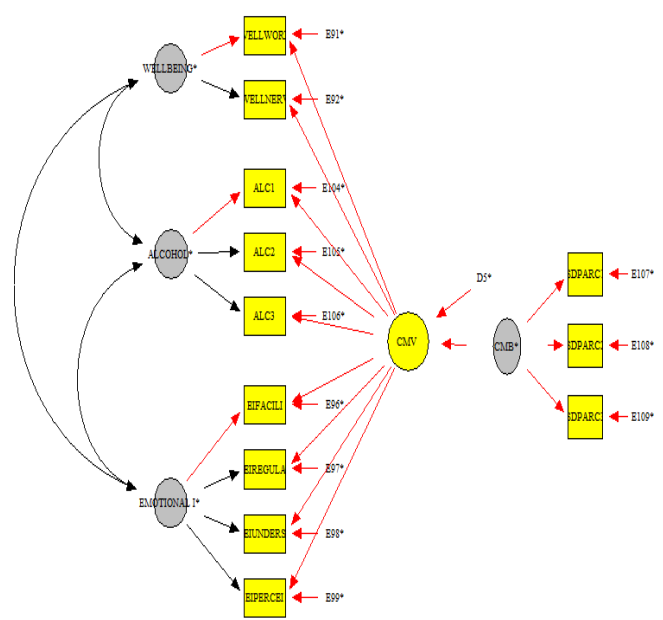

b. Model 1: Baseline model when all the study constructs are correlated without controlling for CMV /CMB.

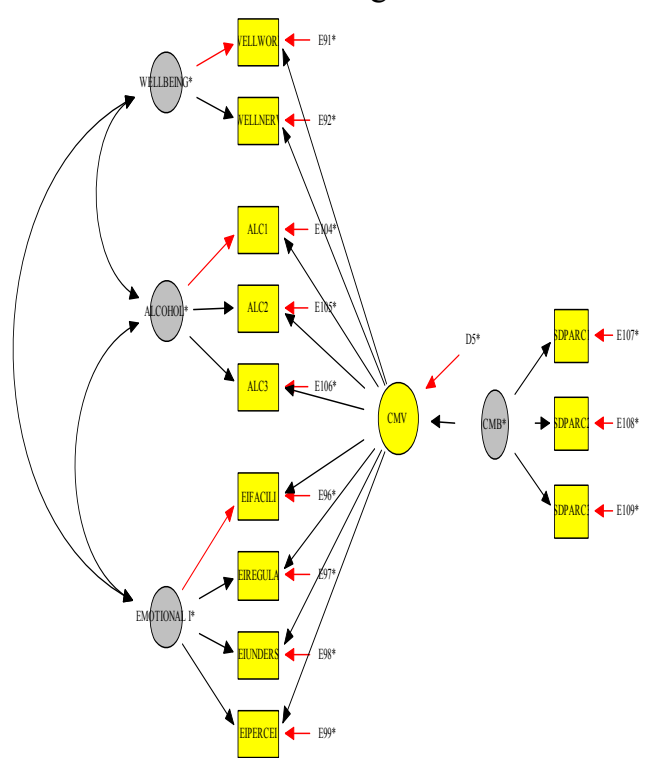

d. Model 3. An integrated model of CMV and CMB with free loadings from CMV to the study indicators.

Figure 4. The proposed and evaluated models for $\mathrm{H} 2$.

Notes: $\mathrm{CMV}=$ common method variance, $\mathrm{CMB}=$ common method bias (social desirability). 
Model 1. This is a baseline model where the three study constructs (well-being, drinking behaviour, and emotional intelligence) correlate with each other but CMV and CMB weights are constrained to zero (Figure 4b). This is used as a comparison model when there is no control for method bias and variance.

Model 2. The second model which will be compared with the baseline model is a constrained model in which CMV and CMB are included in the model but the loadings from CMV to the study indicators are constrained to have equal effects (Figure 4c). CMB (the measured latent method factor) is included in the model as a predictor of CMV. It is assumed that social desirability would be the main source of bias for the study's self-rated questionnaire, when asking about drinking behaviour and emotional intelligence skills. Therefore, this model controls specifically for CMB caused by social desirability, as well as other random sources of CMV.

Model 3. The third model is the same as the previous model but the loadings of CMV to the indicators are allowed to differ (Figure 4d). A comparison of the constrained Model 2 and unconstrained Model 3 with the baseline model tests the amount of CMV for each of the study constructs individually. A comparison of Model 2 (constrained) with Model 3 indicates whether or not the effects of CMV are equal for all three constructs (wellbeing, drinking behaviour and emotional intelligence).

As shown in Table 3, both the constrained CMV (Model 2) $(\mathrm{SB} \times 2 / \mathrm{df}(48)=2.46$, RMSEA $=.07, \mathrm{CFI}=.86)$ and unconstrained CMV (Model 3) $(\mathrm{SB} \chi 2 / \mathrm{df}(39)=1.45$, RMSEA=.04, CFI=.96) describe the data significantly better than the baseline model ( $\mathrm{SB} \chi 2 / \mathrm{df}(52)=3.61$, RMSEA $=.09, \mathrm{CFI}=.73)$ which does not account for any common method variance or bias.

A comparison of Model 2 and Model 3 also showed that Model 2, with varying weights from CMV to the indicators, describes the data significantly better than Model 3, with constrained loadings for CMV.

This suggests that social desirability may not account for all the CMV. It seems that CMV has different effects for the three constructs (wellbeing, drinking behaviour and emotional intelligence), perhaps suggesting that social desirability may not be the only source of CMV.

Table 3. Summary of fit indices of comparison models

\begin{tabular}{|c|c|c|c|c|c|c|c|c|}
\hline Model & $\chi^{2}(d f) *$ & $\chi^{2} / d f$ & $C F I$ & $\begin{array}{c}\text { RMSEA } \\
\text { (CI) }\end{array}$ & Comparison models & $\Delta \chi^{2}$ & $\Delta_{d f}$ & $P$ \\
\hline 1. Baseline & $\begin{array}{c}188.16 \\
(52)\end{array}$ & 3.61 & .73 & $.09(.08, .11)$ & & & & \\
\hline $\begin{array}{l}\text { 2. Constrained } \\
\text { CMV } \dagger\end{array}$ & $\begin{array}{c}117.19 \\
(48)\end{array}$ & 2.44 & .86 & $.07(.05, .08)$ & $\begin{array}{c}\text { Baseline vs. } \\
\text { Constrained CMV } \\
\qquad(1 \vee 2)\end{array}$ & 70.97 & 4 & $<0.001$ \\
\hline \multirow[t]{2}{*}{ 3. $\mathrm{CMB}-\mathrm{CMV}$} & $\begin{array}{c}56.62 \\
(39)\end{array}$ & 1.45 & .96 & $.04(.01, .06)$ & $\begin{array}{c}\text { Baseline vs. } \\
\text { CMB-CMV }(1 \text { v } 3)\end{array}$ & 131.54 & 13 & $<0.001$ \\
\hline & & & & & (2 vs. 3 ) & 60.57 & 9 & $<0.001$ \\
\hline
\end{tabular}

\footnotetext{
*Satorra-Bentler scaled chi-square; † loadings from CMV set to be equal in this model.
}

Table 4 presents the differences between the standardised loadings of the three models. As can be seen, the method variance and method bias (1) do not have equal effects on the indicators and (2) the CMV and CMB had the most inflated emotional intelligence and drinking behaviours indicators when CMV and CMB are controlled in Model 3. 
Table 4. Standardised Factor Loadings for different models compared to baseline

\begin{tabular}{cccccc}
\hline Indicators & $\begin{array}{c}\text { Baseline- } \\
\text { Model 1 }\end{array}$ & $\begin{array}{c}\text { Constrained } \\
\text { CMV-CMB } \\
\text { Model 2 }\end{array}$ & $\begin{array}{c}\text { CMB-CMV } \\
\text { Model 3 }\end{array}$ & $\begin{array}{c}\text { Diff. } \\
\text { Model } \\
\text { 2 vs 1 }\end{array}$ & $\begin{array}{c}\text { Diff. } \\
\text { Model } \\
\text { 3 vs 1 }\end{array}$ \\
\hline Wellbeing: worn & 0.71 & 0.68 & 0.70 & 0.03 & 0.01 \\
out/exhausted & 0.85 & 0.62 & 0.74 & 0.23 & 0.11 \\
Wellbeing: nervous/tense & 0.40 & 0.36 & 0.19 & 0.04 & $0.21^{*}$ \\
EI-Facilitation & 0.92 & 0.71 & 0.69 & $0.21^{*}$ & $0.23^{*}$ \\
EI-Regulation & 0.43 & 0.56 & 0.26 & -0.13 & 0.17 \\
EI-Understanding & 0.46 & 0.62 & 0.29 & -0.16 & $0.25^{*}$ \\
EI-Perceiving & 0.55 & 0.39 & 0.11 & 0.16 & $0.44^{*}$ \\
Alcohol - 1 & 0.93 & 0.66 & 0.25 & $0.27^{*}$ & $0.68^{*}$ \\
Alcohol - 2 & 0.43 & 0.37 & 0.09 & 0.06 & $0.34^{*}$ \\
Alcohol - 3 & & 0.50 & 0.61 & & \\
Social Desirability- 1 & & 0.44 & 0.37 & & \\
Social Desirability- 2 & & 0.55 & 0.48 & & \\
Social Desirability- 3 & & -0.003 & 0.45 & &
\end{tabular}

* differences less than $<20$ is considered as small effects.

This example supports the hypothesis: The SEM-integrated approach allows control for the effects of common method variance and bias due to social desirability as well as other possible sources of CMV as illustrated in Model 3.

\section{Discussion}

The main purpose of this study was to offer some new and comprehensive procedures for controlling CMV which appears to be a common problem in psychological studies. The issue of CMV has become more noticeable with researchers relying more on a single source of data collection and self-report measures. Further analysis was carried on to evaluate the CMV/CMB in the study using the SEM approach. To achieve the later, a SEM approach used for assessing CMV/CMB, introduced by Williams, Hartman, and Cavazotte (2003) and Podsakoff et al. (2003) and further developed by other researchers (e.g. Richardson et al., 2009; Williams et al., 2010).

The results demonstrated three main findings:

CMB (due to social desirability) appears to inflate the reliability measures of the scales.

Controlling the effects of CMV and CMB on the measures used in this study showed the presence of CMV and CMB caused by social desirability.

CMV does not have similar effects on all measures. The measures of emotional intelligence and drinking habits were more influenced by CMV than wellbeing.

Assessing the reliability while controlling for $\mathrm{CMB}$, showed that reliability is inflated by CMB. Although the procedure used in this study was one of the first of its kind for calculating reliability (covariate-based reliability of Bentler, 2014), the results are similar to those of Williams et al. (2010) (in their study of CMV using the reliability decomposition procedure). The results indicate that the presence of CMB threatens the reliability of scales.

Consistent with previous findings (e.g. Podsakoff et al., 2003; Richarson et al., 2009; Williams et al., 2010), it seems that the CFA approach, constrained for CMV and CMB, provides a practical approach for controlling method variances. The findings also demonstrated that forcing equal CMV effects for all measures is not appropriate because it adversely affects the model fit. The findings showed that CMV effects differ depending on the nature of each measure; CMV weights should therefore be allowed to vary. This result is similar to the findings of Williams et al., (2010) but contradicts the equivalent method effects technique proposed by Lindell and Whitney (2001). 


\subsection{Strengths and Limitations.}

This study has some unique strengths. First, it could be considered as one of the first studies of its kind that demonstrated the application of covariate-based and covariate-free reliability in assessing CMB effects on reliability. The procedure appears to provide a very comprehensive and simple demonstration of the method effects in self-reported studies of this kind. This study shows how the effects of CMB on reliability can be assessed. More studies of this type are needed to provide a comprehensive understanding of common method effects on the reliability of measures.

Second, as mentioned before, the application of reliability to CMV assessments first introduced by Williams et al.'s study (2010) using the reliability decomposition formula. However, there are two main limitations with the reliability decomposition formula. First, in practice it is hard to use the formula since it involves manual calculations. Second, it has some limitations when substantive factors are uncorrelated with each other, and/or when substantive and method factors are mutually uncorrelated. The proposed covariate-based and covariate-free reliability procedure by Bentler (2014) overcomes these limitations and can be easily calculated using EQS.

Third, this is one of the first studies of its kind that integrates a measured and unmeasured latent variable procedure (Podsakoff et al., 2003), controlling for CMV and CMB. The procedure appears to provide a very comprehensive way for controlling method effects in self-reported studies of this kind. But, there is a need for further studies in order to shed more light on this procedure.

Fourth, using SEM while controlling for $\mathrm{CMV} / \mathrm{CMB}$, marks the beginning of a new era. As acknowledged by scholars (Richardson et al., 2009; Williams et al., 2010; Podsakoff et al., 2003), it is now possible to assess the effects of CMV/CMB on parameter estimates using SEM. Further simulation studies are needed to assess the procedure in different conditions and using different marker variables.

Having said this, this study is not without weakness and limitations. The marker variable choice for CMB (in this study, social desirability) is controversial. Some scholars believe that the marker variable should not have any relationship with other substantive constructs while others believe the opposite (e.g. Lindell and Whitney, 2001; Richardson et al., 2009; Williams et al., 2010). In their review of previous studies, Williams et al., (2010) demonstrated that researchers use a broad range of variables as marker variables for CMB. They concluded that “... no consideration has been given to the role of theory associated with method processes to guide the selection of marker variables and the understanding of their effects" (p. 505). Further studies are needed to determine the best criteria for choosing an appropriate marker variable when controlling for CMB.

\section{References}

Abraham, R. (1999) Emotional intelligence in organizations: a conceptualization. Genetic, Social and General Psychology Monographs, 125, 209-227.

Avolio, B. J., Yammarino, F. J. \& Bass, B. M. (1991). Identifying common methods variance with data collected from a single source: An unresolved sticky issue. Journal of management, 17, 571-586.https://doi.org/10.1177/014920639101700303

Bagozzi, R. P. \& Yi, Y. (1991). Multitrait- Multimethod matrices in consumer research. Journal of Consumer Research, 17(4), 426-439.https://doi.org/10.1086/208568

Bentler, P. M. (2006). EQS 6 Structural Equations Program Manual. Encino, CA: multivariate Software, Inc. Los Angeles.

Bentler, P. M. (2014). Covariate-free and Covariate-based Reliability. The 79th Annual Meeting of the Psychometric Society will be held in Madison, Wisconsin from July 21st until July 25th, 2014.

Bentler, P. M. (2016). Covariate-free and Covariate-dependent Reliability. Psychometrika, 81(4), 907-920. https://doi.org/10.1007/s11336-016-9524-y.

Ciarrochi J., Chan A.Y.C. \& Caputi P. (2000). A critical evaluation of the emotional intelligence concept. Personality and Individual Differences, 28, 1477-1490.https://doi.org/10.1016/S0191-8869(99)00119-1

Cox, T., Thirlaway, M., Gotts, G. \& Cox, S. (1983). The nature and assessment of general well-being. Journal of Psychosomatic Research, 27(5), 353-359.https://doi.org/10.1016/0022-3999(83)90066-1

Donaldson, S. I. \& Grant-Vallone, E. J. (2002). Understanding self-report bias in organizational behavior research. Journal of Business and Psychology, 17(2), 245-260. https://doi.org/10.1023/A:1019637632584

Doty, D. H. \& Glick, W. H. (1998). Common method bias: Does common methods variance really bias results? Organizational Research Methods, 1(4), 374-406. https://doi.org/10.1023/A:1019637632584 
Ganster, D. C., Hennessey, H. W. \& Luthans, F. (1983). Social desirability response effects: Three alternative models. The Academy of Management Journal, 26(2), 321-331. https://doi.org/10.2307/255979

Glick, W. H., Jenkins, G. D., Jr. \& Gupta, N. (1986). Method versus substance: How strong are underlying relationships between job characteristics and attitudinal outcomes? Academy of Management Journal, 29(3), 441-464. https://doi.org/10.5465/256218

Lindell, M. K. \& Whitney, D. J. (2001). Accounting for common method variance in cross-sectional research designs. Journal of Applied Psychology, 86, 114-121.https://doi.org/10.1037/0021-9010.86.1.114

Malhotra, N. K., Kim, S. S. \& Patil, A. (2006). Commom method variance in IS research: A comparison of alternative approaches and a reanalysis of past research. Management Science, 52(12), 1865-1883. https://doi.org/10.1287/mnsc. 1060.0597

Meade, A. W., Watson, A. M. \& Kroustalis, C. M. (2007). Assessing common methods bias in organisational research. Paper presented at the 22nd Annual Meeting of the Society for Industrial and Organizational Psychology, New York. https://doi.org/10.1037/e518532013-132

Petrides K.V. \& Furnham A. (2000) On the dimensional structure of emotional intelligence. Personality and Individual Differences, 29, 313-320.https://doi.org/10.1016/S0191-8869(99)00195-6

Podsakoff, P. M., MacKenzie, S. B., Lee, J.-Y. \& Podsakoff, N. P. (2003). Common method biases in behavioral research: A critical review of the literature and recommended remedies. Journal of Applied Psychology, 88(5), 879-903. https://doi.org/10.1016/S0191-8869(99)00195-6

Podsakoff, P. M. \& Organ, D. W. (1986). Self-reports in organizational research: Problems and prospects. Journal of Management, 12, 531-544. https://doi.org/10.1177/014920638601200408

Richardson, H. A., Simmering, M. J. \& Sturman, M. C. (2009). A tale of three perspectives: Examining post hoc statistical techniques for detection and correction of common method variance. Organizational Research Methods, 12, 762-800.https://doi.org/10.1177/1094428109332834

Satorra, A. \& Bentler, P. M. (1988). Scaling corrections for statistics in covariance structure analysis (UCLA Statistics Series 2). Los Angeles: UCLA, Department of Psychology.

Satorra, A. \& Bentler, P. M. (1994). Corrections to test statistics and standard errors in covariance structure analysis. In A. Eye \& C. C. Colgg (Eds), Latent variables analysis: Applications for developmental research (399-419).

Saunders, J.B., Aasland, O.G., Babor, T.F., de la Fuente, J.R. \& Grant, M. (1993). Development of the Alcohol Use Disorders Identification Test (AUDIT): WHO collaborative project on early detection of persons with $\begin{array}{llllll}\text { harmful alcohol } & \text { consumption. } & \text { II. } & \text { Addiction, } & 88, & \text { 791-804. }\end{array}$ https://doi.org/10.1111/j.1360-0443.1993.tb02093.x

Schriesheim, C. A., Kinicki, A. J. \& Schriesheim, J. F. (1979). The effect of leniency on leader behavior descriptions. Organizational Behavior and Human Performance, 23, 1-29. https://doi.org/10.1016/0030-5073(79)90042-4

Schutte N.S. \& Malouff J.M. (1999) Measuring Emotional Intelligence and Related Constructs. E. Mellen Press, Lewiston, NY.

Schutte N.S., Malouff J.M., Hall L.E., Haggerty D.J., Cooper J.T., Golden C.J. \& Dornheim L. (1998) Development and validation of a measure of emotional intelligence. Personality and Individual Differences, 25, 167-177.https://doi.org/10.1016/S0191-8869(98)00001-4

Stober, J. (2001). The social desirability scale-17 (SDS17): Convergent validity, discriminant validity, and relationship with age. European Journal of Psychological Assessment, 17(3), 222-232.https://doi.org/10.1027//1015-5759.17.3.222

Thomas, K. W. \& Kilmann, R. H. (1975). The social desirability variable in organizational research: An alternative explanation for reported findings. The Academy of Management Journal, 18(4), 741-752. https://doi.org/10.2307/255376

Werts, C. E., Linn, R. L. \& Joreskog, K. G. (1974). Interclass reliability estimates: Testing structural assumptions. Educational and Psychological Measurement, 34 , 25-33.https://doi.org/10.1177/001316447403400104 
Williams, L. J., Cote, J. A. \& Buckley, M. R. (1989). Lack of method variance in self-reported affect and perceptions at work: Reality or artifact? Journal of Applied Psychology, 74(3), $462-468$. https://doi.org/10.1037//0021-9010.74.3.462

Williams, L. J., Hartman, N. \& Cavazotte, F. (2010). Technique Method Variance and Marker Variables: A Review and Comprehensive CFA Marker. Organizational Research Methods, 13(3), 477-514.https://doi.org/10.1177/1094428110366036

Winkler, J. D., Kanouse, D. E. \& Ware, J. E., Jr. (1982). Controlling for acquiescence response set in scale development. Journal of Applied Psychology, 67(5), 555-561. https://doi.org/10.1037/0021-9010.67.5.555

\section{Copyrights}

Copyright for this article is retained by the author(s), with first publication rights granted to the journal.

This is an open-access article distributed under the terms and conditions of the Creative Commons Attribution license (http://creativecommons.org/licenses/by/3.0/). 